\title{
Prognostic values of normal preoperative serum cancer markers for gastric cancer
}

\author{
Fan Feng ${ }^{1, *}$, Li Sun ${ }^{1, *}$, Zhen Liu ${ }^{1, *}$, Shushang Liu ${ }^{1}$, Gaozan Zheng ${ }^{1}$, Guanghui $\mathrm{Xu}^{1}$,

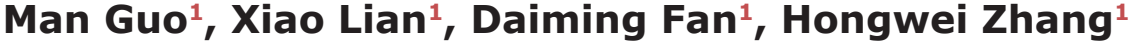 \\ ${ }^{1}$ Department of Digestive Surgery, Xijing Hospital, Fourth Military Medical University, 710032, Xi'an, Shaanxi, China \\ *These authors have contributed equally to this work
}

Correspondence to: Hongwei Zhang, email: zhanghwfmmu@126.com

Keywords: gastric cancer, CA 19-9, AFP, CA 125, prognosis

Received: May 29, $2016 \quad$ Accepted: July 28, 2016

Published: August 12, 2016

\section{ABSTRACT}

We examined the prognostic value of normal levels of four serum cancer markers, carcinoembryonic antigen (CEA), carbohydrate associated antigen (CA199), alpha-fetoprotein (AFP) and cancer antigen 125 (CA125), in gastric cancer patients. Among 1927 gastric cancer patients enrolled in this study, 1477 were male $(76.6 \%)$ and 450 were female $(23.4 \%)$. The median age was 57 years (range 20-86). Clinicopathological features and survival times were recorded, and the association between CEA, CA19-9, AFP, and CA125 levels and patient prognosis was analyzed. The optimal cut-off values were 0.71 for CEA $(P=0.317), 9.22$ for CA19-9 $(P=0.009), 3.76$ for AFP $(P=0.008)$ and 15.65 for CA125 $(P=0.006)$. Serum CA19-9 levels correlated with gender, age, and tumor depth (all $P<0.05$ ); AFP levels correlated with pathological type $(P=0.005)$; and CA125 levels correlated with gender, tumor size, pathological type, tumor depth and lymph node metastasis (all P<0.05). Relatively high levels of CA19-9, AFP and CA125, still within the normal range, were all associated with poor prognosis (5-year overall survival: $70.6 \%$ vs $64.2 \%, P<0.001 .69 .6 \%$ vs $54.5 \%, P=0.011 .70 .2 \%$ vs $54.9 \%, P<0.001$ ). However, only CA19-9 and AFP levels were independent prognostic predictors. We conclude that the combined assessment of CA19-9, AFP and CA125 levels could have prognostic value in gastric cancer $(P<0.001)$.

\section{INTRODUCTION}

Although the incidence of gastric cancer has decreased worldwide, it is still the fifth most common malignancy and the third leading cause of cancer-related mortality in the world [1]. Surgical resection with extended lymph node clearance remains the only curative therapy for non-metastatic gastric cancer. Even with advances in surgical techniques and adjuvant therapy, the prognosis of advanced gastric cancer is still discouraging due to late diagnosis [2].

A variety of factors are well recognized as prognostic indicators for gastric cancer, including tumor size, tumor depth, lymph node metastasis (LNM), and vessel involvement $[3,4]$. In addition, elevated levels of preoperative tumor markers, including CEA [5], CA19-
9 [6], AFP [7], and CA125 [8], were demonstrated to be associated with gastric cancer prognosis. However, the prognostic values of these tumor markers within the normal range have not yet been investigated. Therefore, the purpose of this study was to explore the prognostic values of normal, preoperative CEA, CA19-9, AFP, and CA125 levels in gastric cancer.

\section{RESULTS}

There were 1477 males (76.6\%) and 450 females $(23.4 \%)$ enrolled in this study. The patient age ranged from 20-86 years (median, 57; mean, 56.6). The followup time ranged from 1 to 75 months (median, 26.0; mean, 29.7). The 1-, 3- and 5-year overall survival (OS) rates were $93.7 \%, 75.6 \%$ and $68.0 \%$, respectively (Figure 1). 
The optimal cut-off values of normal serum CEA, CA199, AFP, and CA125 for the prognosis of gastric cancer were calculated using X-tile software and are shown in Figures 2-5. The optimal cut-off values were: 0.71 for CEA $(\mathrm{P}=0.317), 9.22$ for CA19-9 $(\mathrm{P}=0.009), 3.76$ for AFP $(\mathrm{P}=0.008)$, and 15.65 for $\mathrm{CA} 125(\mathrm{P}=0.006)$.

Thus, CA19-9, AFP, and CA125 were tested in univariate and multivariate analyses as prognostic predictors of gastric cancer. The univariate analysis showed that age, tumor size, pathological type, tumor depth, LNM, CA19-9, AFP, and CA125 were risk factors for gastric cancer (Table 1). However, only age, tumor size, pathological type, tumor depth, LNM, CA19-9, and
AFP were independent prognostic factors according to multivariate analysis (Table 2). Moreover, relatively high levels of CA19-9, AFP, and CA125 were associated with poor prognosis (5-year OS: $70.6 \%$ vs $64.2 \%, \mathrm{P}<0.001$. $69.6 \%$ vs $54.5 \%, \mathrm{P}=0.011 .70 .2 \%$ vs $54.9 \%, \mathrm{P}<0.001$; Figures 6-8). Clinicopathological features between the high- and low-level groups of CA19-9, AFP, and CA125 were analyzed and are summarized in Tables 3-5, respectively. Serum CA19-9 levels were correlated with gender, age, and tumor depth (all $\mathrm{P}<0.05$ ), serum AFP levels were correlated with pathological type $(\mathrm{P}=0.005)$, and serum CA125 levels were correlated with gender,

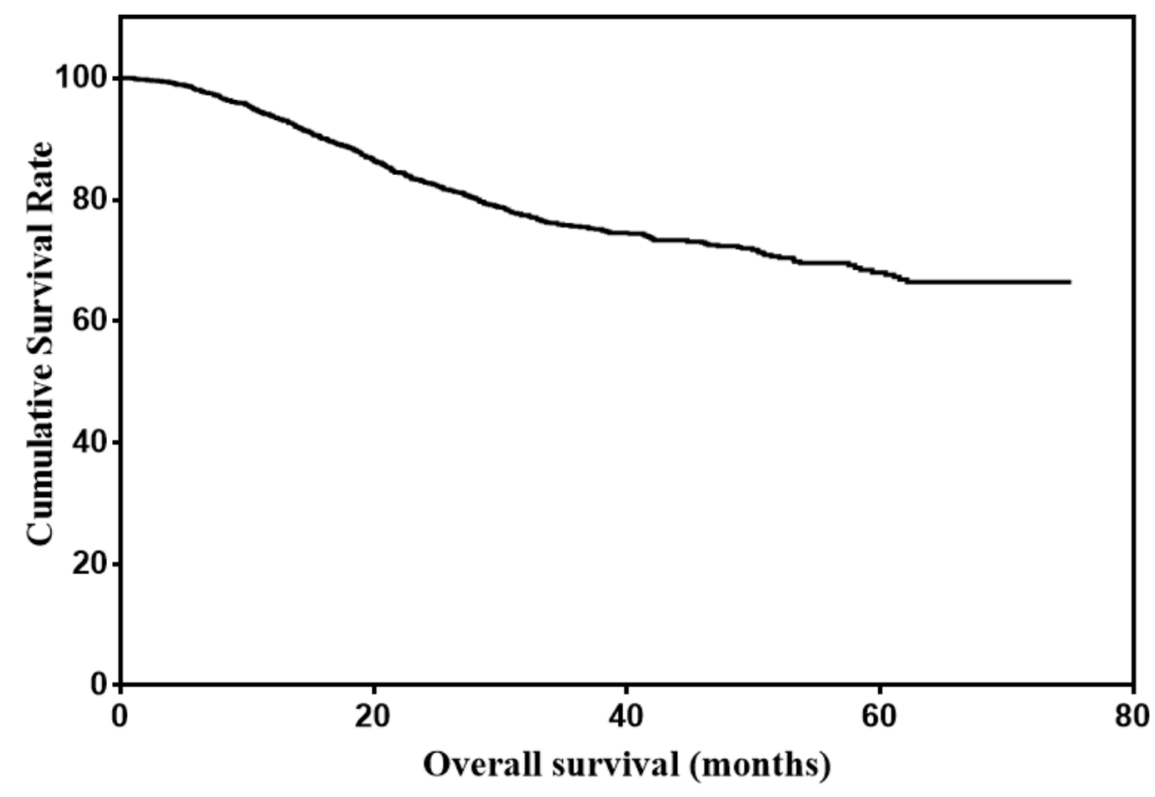

Figure 1: Overall survival of gastric cancer patients with normal serum CEA, CA19-9, AFP, and CA125 levels.
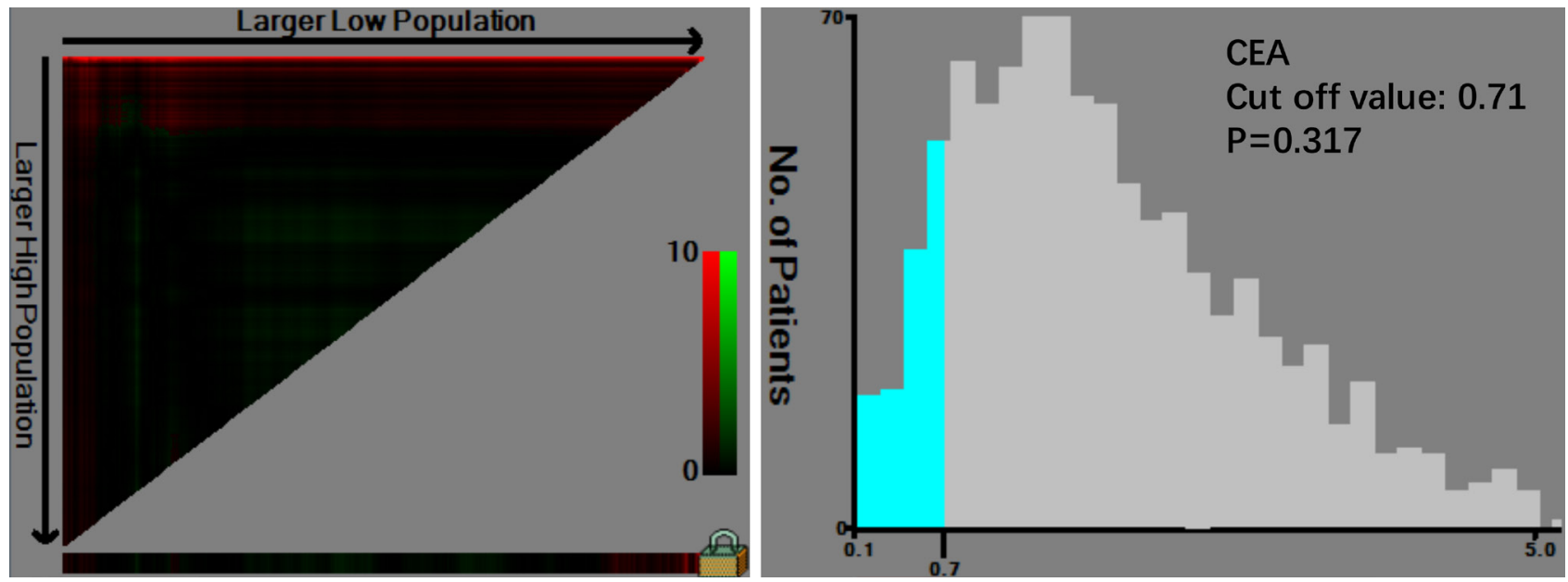

Figure 2: Cut-off value of serum CEA for the prognosis of gastric cancer as calculated using X-tile. 

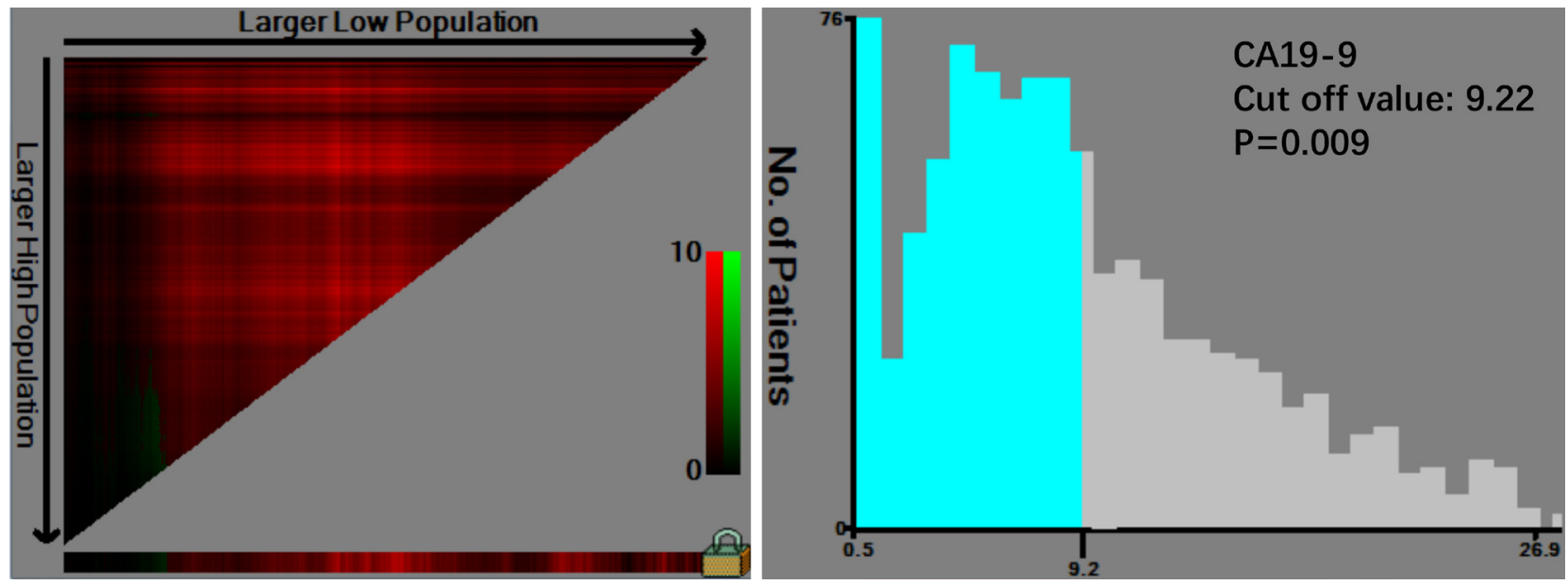

Figure 3: Cut-off value of serum CA19-9 for the prognosis of gastric cancer as calculated using X-tile.
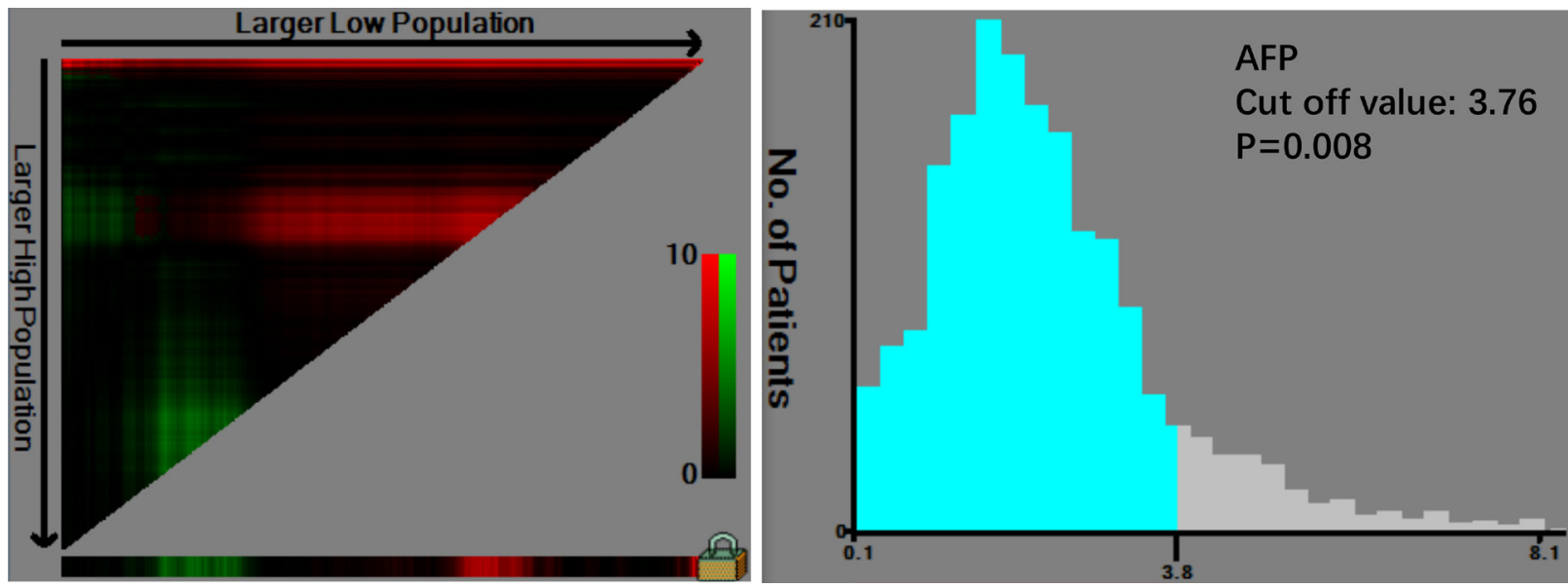

Figure 4: Cut-off value of serum AFP for the prognosis of gastric cancer as calculated using X-tile.
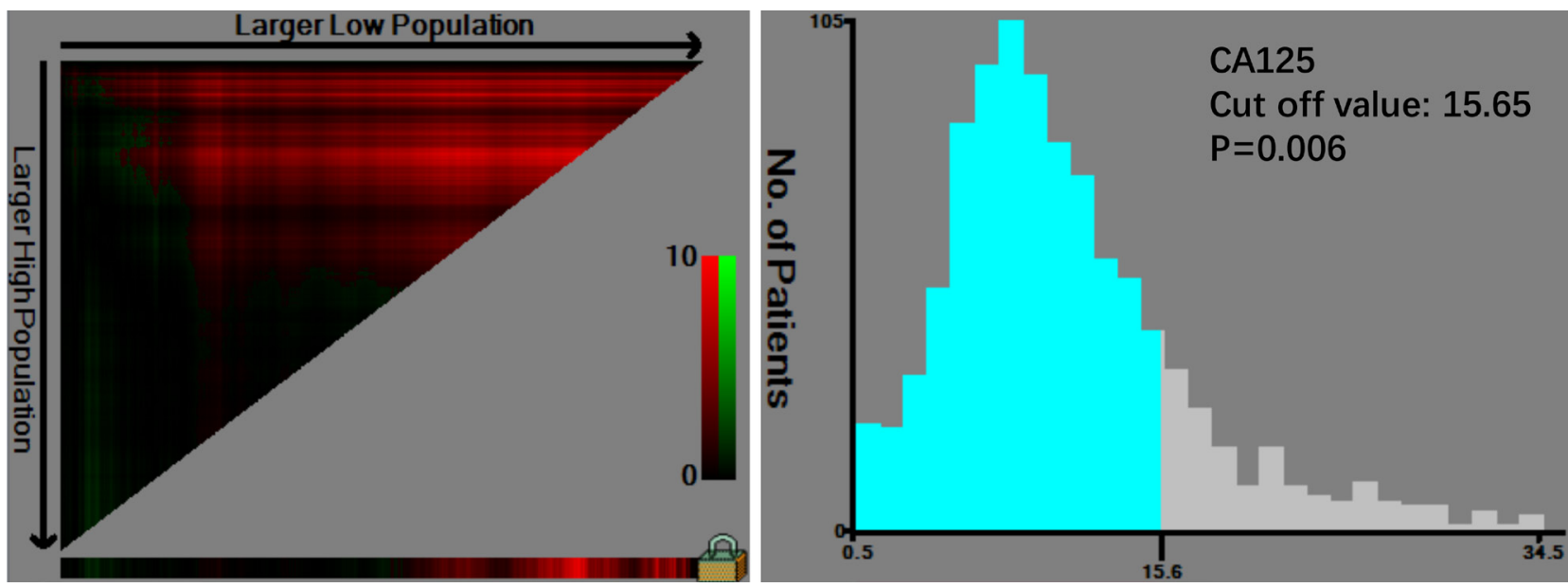

Figure 5: Cut-off value of serum CA125 for the prognosis of gastric cancer as calculated using X-tile. 
Table 1: Univariate analysis of risk factors for prognosis of gastric cancer

\begin{tabular}{lccc}
\hline Prognostic factors & $\boldsymbol{\beta}$ & Hazard ratio (95\% CI) & P value \\
\hline Gender & 0.226 & $1.253(0.999-1.572)$ & 0.051 \\
Age & 0.234 & $1.264(1.035-1.542)$ & 0.021 \\
Tumor location & -0.037 & $0.964(0.868-1.070)$ & 0.488 \\
Tumor size & 1.291 & $3.636(2.977-4.441)$ & 0.000 \\
Pathological type & 0.554 & $1.740(1.509-2.007)$ & 0.000 \\
Tumor depth & 0.872 & $2.393(2.124-2.696)$ & 0.000 \\
Lymph node metastasis & 0.777 & $2.174(1.986-2.380)$ & 0.000 \\
CEA & -0.213 & $0.808(0.606-1.077)$ & 0.808 \\
CA19-9 & 0.376 & $1.456(1.194-1.777)$ & 0.000 \\
AFP & 0.348 & $1.417(1.083-1.852)$ & 0.011 \\
CA125 & 0.493 & $1.637(1.286-2.085)$ & 0.000 \\
\hline
\end{tabular}

Table 2: Multivariate analysis of risk factors for prognosis of gastric cancer

\begin{tabular}{lccc}
\hline Prognostic factors & $\boldsymbol{\beta}$ & Hazard ratio (95\% CI) & P value \\
\hline Age & 0.247 & $1.280(1.005-1.630)$ & 0.046 \\
Tumor size & 0.623 & $1.865(1.447-2.405)$ & 0.000 \\
Pathological type & 0.262 & $1.300(1.030-1.640)$ & 0.027 \\
Tumor depth & 0.436 & $1.547(1.293-1.850)$ & 0.000 \\
Lymph node metastasis & 0.520 & $1.683(1.472-1.923)$ & 0.000 \\
CA19-9 & 0.331 & $1.393(1.096-1.770)$ & 0.007 \\
AFP & 0.459 & $1.583(1.166-2.149)$ & 0.003 \\
\hline
\end{tabular}

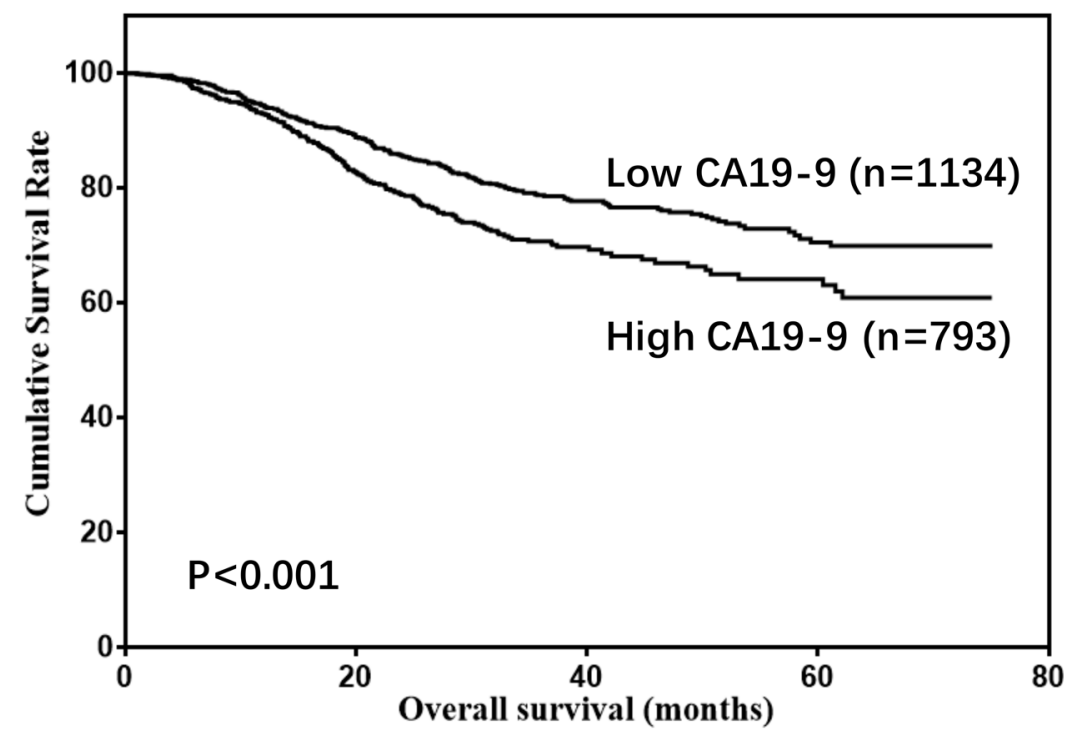

Figure 6: Overall survival of gastric cancer patients according to CA19-9 levels. 
tumor size, pathological type, tumor depth, and LNM (all $\mathrm{P}<0.05)$.

The prognostic value of the combination of CA19-9, AFP, and CA125 for gastric cancer was also evaluated. Gastric cancer patients were divided into four groups: Group 1) low CA19-9, low AFP and low CA125; Group 2) high CA19-9, low AFP, and low CA125; or low CA19-9, high AFP, and low CA125, or low CA19-9, low AFP, and high CA125; Group 3) high CA19-9, high AFP, and low CA125, or high CA19-9, low AFP, and high CA125; or low CA19-9, high AFP, and high CA125; and Group 4) high CA19-9, high AFP, and high CA125. As shown in Figure 9, OS rates were gradually reduced along with increasing levels of CA199, AFP, and CA125 (P<0.001).

\section{DISCUSSION}

A large number of studies have investigated the predictive value of elevated preoperative serum CEA, CA19-9, AFP, and CA125 levels for the prognosis of gastric cancer. However, no studies have investigated the prognostic value of normal CEA, CA19-9, AFP, and CA125 levels in gastric cancer patients. The present study

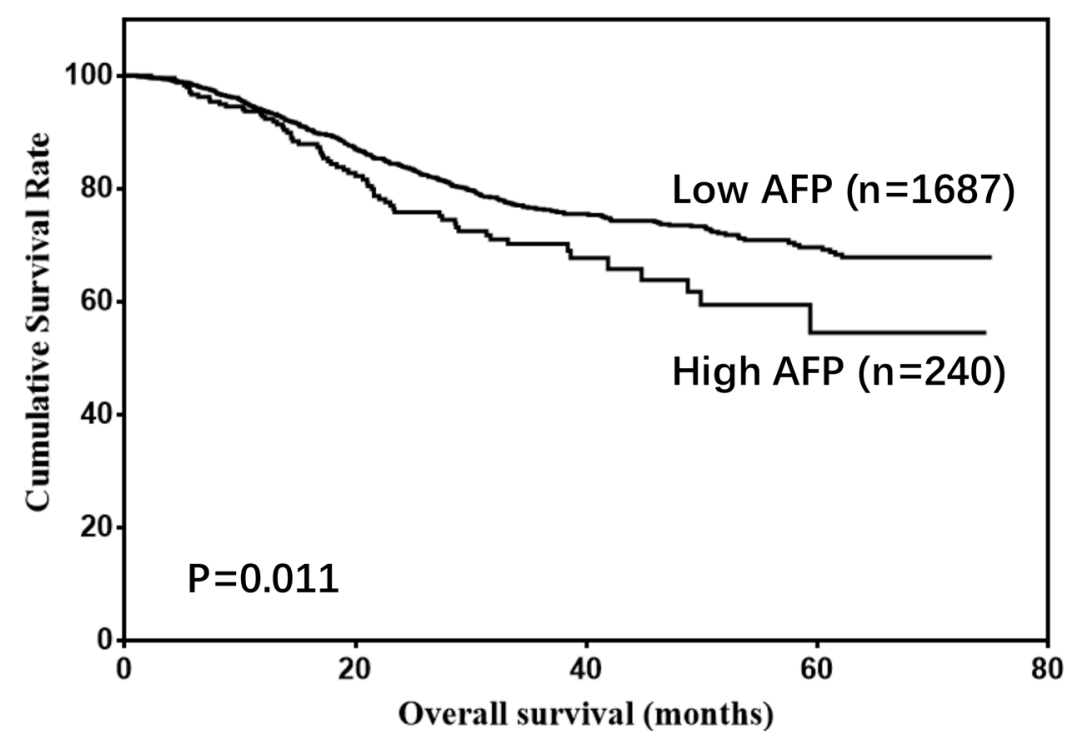

Figure 7: Overall survival of gastric cancer patients according to AFP levels.

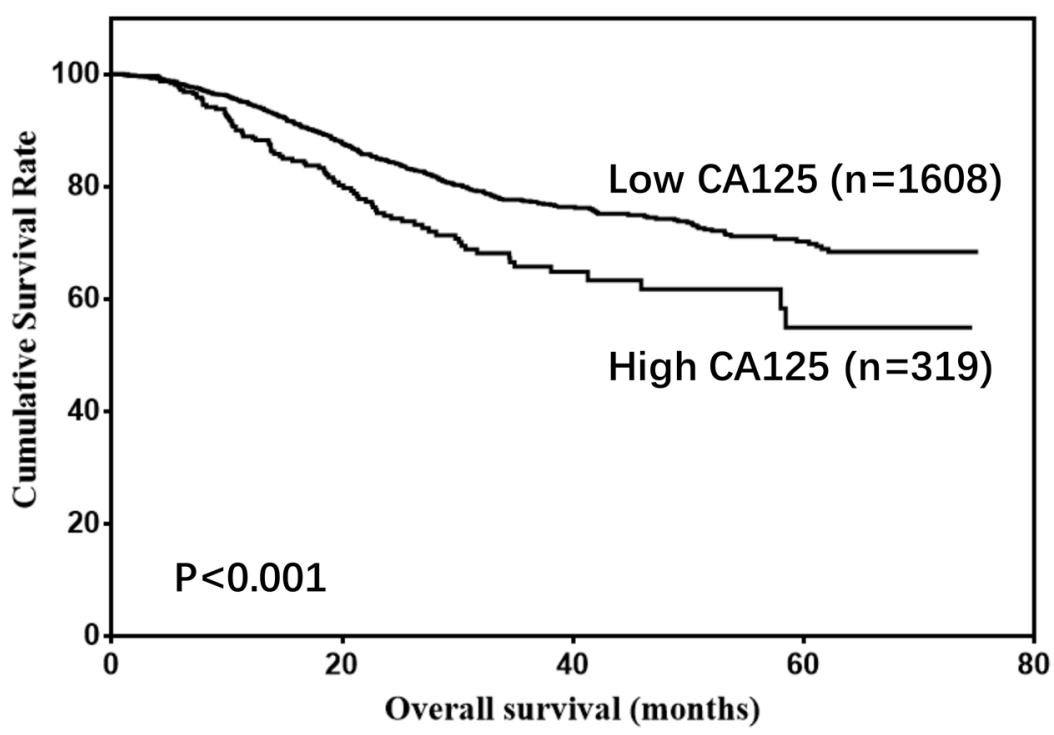

Figure 8: Overall survival of gastric cancer patients according to CA125 levels. 
Table 3: Comparison of clinicopathological characteristics between two groups

\begin{tabular}{|c|c|c|c|}
\hline Characteristics & $\begin{array}{c}\text { Low CA19-9 } \\
(n=1134)\end{array}$ & $\begin{array}{l}\text { High CA19-9 } \\
\quad(n=793)\end{array}$ & $\begin{array}{c}P \\
\text { value }\end{array}$ \\
\hline Gender & & & 0.013 \\
\hline Male & 892 & 585 & \\
\hline Female & 242 & 208 & \\
\hline Age & & & 0.000 \\
\hline$\leq 60$ & 744 & 425 & \\
\hline$>60$ & 390 & 368 & \\
\hline Tumor location & & & 0.360 \\
\hline Upper third & 290 & 218 & \\
\hline Middle third & 218 & 131 & \\
\hline Lower third & 538 & 389 & \\
\hline Entire & 88 & 55 & \\
\hline Tumor size (cm) & & & 0.369 \\
\hline$\leq 5$ & 858 & 614 & \\
\hline$>5$ & 276 & 179 & \\
\hline Pathological type & & & 0.890 \\
\hline Well differentiated & 145 & 100 & \\
\hline Moderately differentiated & 276 & 187 & \\
\hline Poorly differentiated & 670 & 480 & \\
\hline Signet ring cell or Mucinous & 43 & 26 & \\
\hline Tumor depth & & & 0.004 \\
\hline $\mathrm{T} 1$ & 307 & 201 & \\
\hline $\mathrm{T} 2$ & 192 & 134 & \\
\hline $\mathrm{T} 3$ & 384 & 228 & \\
\hline $\mathrm{T} 4$ & 251 & 230 & \\
\hline Lymph node metastasis & & & 0.052 \\
\hline N0 & 527 & 319 & \\
\hline N1 & 199 & 148 & \\
\hline N2 & 170 & 134 & \\
\hline N3 & 238 & 192 & \\
\hline
\end{tabular}

found that relatively high levels of CA19-9, AFP, and CA125 within the normal limits were associated with a poor prognosis in gastric cancer.

Elevated preoperative serum CEA, CA19-9, AFP, and CA125 have been previously associated with a poor prognosis in gastric cancer. A meta-analysis of 14,651 gastric cancer patients found that elevated serum CEA was an independent prognostic risk factor [5]. Similarly, another meta-analysis of 11,408 gastric cancer patients showed that elevated serum CA19-9 was associated with a poor prognosis [9]. Elevated serum AFP has also been associated with a poor prognosis in gastric cancer, and it 
Table 4: Comparison of clinicopathological characteristics between two groups

\begin{tabular}{|c|c|c|c|}
\hline Characteristics & $\begin{array}{l}\text { Low AFP } \\
(n=1687)\end{array}$ & $\begin{array}{c}\text { High AFP } \\
(n=240)\end{array}$ & $\begin{array}{c}P \\
\text { value }\end{array}$ \\
\hline Gender & & & 0.105 \\
\hline Male & 1303 & 174 & \\
\hline Female & 384 & 66 & \\
\hline Age & & & 0.235 \\
\hline$\leq 60$ & 1015 & 154 & \\
\hline$>60$ & 672 & 86 & \\
\hline Tumor location & & & 0.746 \\
\hline Upper third & 444 & 64 & \\
\hline Middle third & 300 & 49 & \\
\hline Lower third & 818 & 109 & \\
\hline Entire & 125 & 18 & \\
\hline Tumor size (cm) & & & 0.304 \\
\hline$\leq 5$ & 1295 & 177 & \\
\hline$>5$ & 392 & 63 & \\
\hline Pathological type & & & 0.005 \\
\hline Well differentiated & 209 & 36 & \\
\hline Moderately differentiated & 426 & 37 & \\
\hline Poorly differentiated & 989 & 161 & \\
\hline Signet ring cell or Mucinous & 63 & 6 & \\
\hline Tumor depth & & & 0.185 \\
\hline $\mathrm{T} 1$ & 439 & 69 & \\
\hline $\mathrm{T} 2$ & 294 & 32 & \\
\hline $\mathrm{T} 3$ & 542 & 70 & \\
\hline $\mathrm{T} 4$ & 412 & 69 & \\
\hline Lymph node metastasis & & & 0.949 \\
\hline N0 & 744 & 102 & \\
\hline N1 & 302 & 45 & \\
\hline N2 & 267 & 37 & \\
\hline N3 & 374 & 56 & \\
\hline
\end{tabular}

can predict liver metastasis after radical resection $[7,10$, 11]. Elevated serum CA125 levels have been associated with peritoneal metastasis of gastric cancer [12, 13], and elevated CA125 in peritoneal lavage was associated with peritoneal dissemination and a poor prognosis [14].
Although gastric cancer patients with normal, preoperative serum CEA, CA19-9, AFP, and CA125 had favorable prognoses, the prognostic value of relatively high levels of the four tumor markers within the normal limits was important to test. We found that relatively high levels of CA19-9, AFP, and CA125 were associated 
Table 5: Comparison of clinicopathological characteristics between two groups

\begin{tabular}{|c|c|c|c|}
\hline Characteristics & $\begin{array}{c}\text { Low CA125 } \\
(n=1608)\end{array}$ & $\begin{array}{l}\text { High CA125 } \\
\quad(n=319)\end{array}$ & $\begin{array}{c}\mathbf{P} \\
\text { value }\end{array}$ \\
\hline Gender & & & 0.000 \\
\hline Male & 1268 & 209 & \\
\hline Female & 340 & 110 & \\
\hline Age & & & 0.345 \\
\hline$\leq 60$ & 983 & 186 & \\
\hline$>60$ & 625 & 133 & \\
\hline Tumor location & & & 0.334 \\
\hline Upper third & 429 & 79 & \\
\hline Middle third & 295 & 54 & \\
\hline Lower third & 772 & 155 & \\
\hline Entire & 112 & 31 & \\
\hline Tumor size $(\mathrm{cm})$ & & & 0.000 \\
\hline$\leq 5$ & 1255 & 217 & \\
\hline$>5$ & 353 & 102 & \\
\hline Pathological type & & & 0.038 \\
\hline Well differentiated & 217 & 28 & \\
\hline Moderately differentiated & 392 & 71 & \\
\hline Poorly differentiated & 939 & 211 & \\
\hline Signet ring cell or Mucinous & 60 & 9 & \\
\hline Tumor depth & & & 0.003 \\
\hline $\mathrm{T} 1$ & 436 & 72 & \\
\hline $\mathrm{T} 2$ & 287 & 39 & \\
\hline $\mathrm{T} 3$ & 504 & 108 & \\
\hline $\mathrm{T} 4$ & 381 & 100 & \\
\hline Lymph node metastasis & & & 0.000 \\
\hline N0 & 739 & 107 & \\
\hline N1 & 286 & 61 & \\
\hline $\mathrm{N} 2$ & 252 & 52 & \\
\hline N3 & 331 & 99 & \\
\hline
\end{tabular}

with poor prognosis of gastric cancer. However, serum CEA did not have prognostic value. Further, the combination of relatively high levels of CA19-9, AFP, and CA125 increased the prognostic value for gastric cancer, even though the levels were all within the normal limits. These results provide new insights into the prognosis of gastric cancer patients with normal, preoperative tumor markers.

Levels of CEA, CA19-9, AFP, and CA125 are also widely used to monitor recurrence or metastasis of 
gastric cancer after radical gastrectomy. Patients with normal postoperative CEA levels have a better prognosis [15]. Similarly, Kwon et al. reported that postoperative normalization of CA19-9 can be a surrogate for potentially curative surgical treatment and can be used as a prognostic factor for gastric cancer [16]. However, the predictive value of these tumor markers within normal limits after radical gastrectomy still needs further investigation.

A strong correlation between tumor marker levels and clinicopathological characteristics has been reported previously. Serum CEA levels were associated with tumor depth, LNM, TNM stage, and liver metastasis $[17,18]$. Serum CA19-9 levels were also associated with tumor depth and LNM, as well as lymphatic-vascular invasion $[19,20]$. Serum AFP levels were associated with LNM, vascular invasion, and liver metastasis [21], and serum CA125 was correlated with vascular invasion, LNM, and tumor stage [22]. We found that serum CA19-9 levels were correlated with gender, age, and tumor depth, serum AFP levels were correlated with pathological type, and serum CA125 levels were correlated with gender, tumor size, pathological type, tumor depth, and LNM.

There are several limitations to our study. First, it was a retrospective study of a single center's experience. Multi-center studies are needed to verify these findings. Second, the sample size was not large, especially for the patients with high levels of CA19-9, AFP, and CA125, which may result in bias during analysis. Third, the prognostic value of normal, CEA, CA19-9, AFP, and CA125 levels for gastric cancer patients after radical gastrectomy during follow-up were not investigated.
Nonetheless, we conclude that relatively high levels of preoperative serum CA19-9, AFP, and CA125 within the normal limits are associated with poor prognosis of gastric cancer. Thus, the combination of CA19-9, AFP and CA125 levels could further increase the predictive value for the prognosis of gastric cancer.

\section{MATERIALS AND METHODS}

This study was performed in the Xijing Hospital of Digestive Diseases affiliated with the Fourth Military Medical University. From September 2008 to March 2015, a total of 1927 gastric cancer patients were enrolled. The inclusion criteria were as follows: 1) no neoadjuvant chemotherapy, 2) radical D2 gastrectomy, 3) normal, preoperative serum CEA, CA19-9, AFP, and CA125 levels, and 4) with follow-up data. This study was approved by the Ethics Committee of Xijing Hospital, and written informed consent was obtained from all patients before surgery.

The four serum tumor markers were detected within 7 days before surgery. The cut-off values for serum CEA, CA19-9, AFP, and CA125 were $5 \mathrm{ng} / \mathrm{ml}, 27 \mathrm{U} / \mathrm{ml}$, $8.1 \mathrm{ng} / \mathrm{ml}, 35 \mathrm{U} / \mathrm{ml}$. Preoperative data including gender, age, tumor location, serum CEA, serum CA19-9, serum AFP and serum CA125 were recorded. All patients were treated with proximal, distal, or total gastrectomy with D2 lymphadenectomy. The surgical procedure was based on the recommendations of the Japanese Gastric Cancer Treatment Guidelines [23]. The depth of primary tumor and degree of lymph node involvement were defined according to the TNM classification. Tumor size, differentiation status, tumor depth, and LNM data were also collected during the pathological examination. The patients remained in

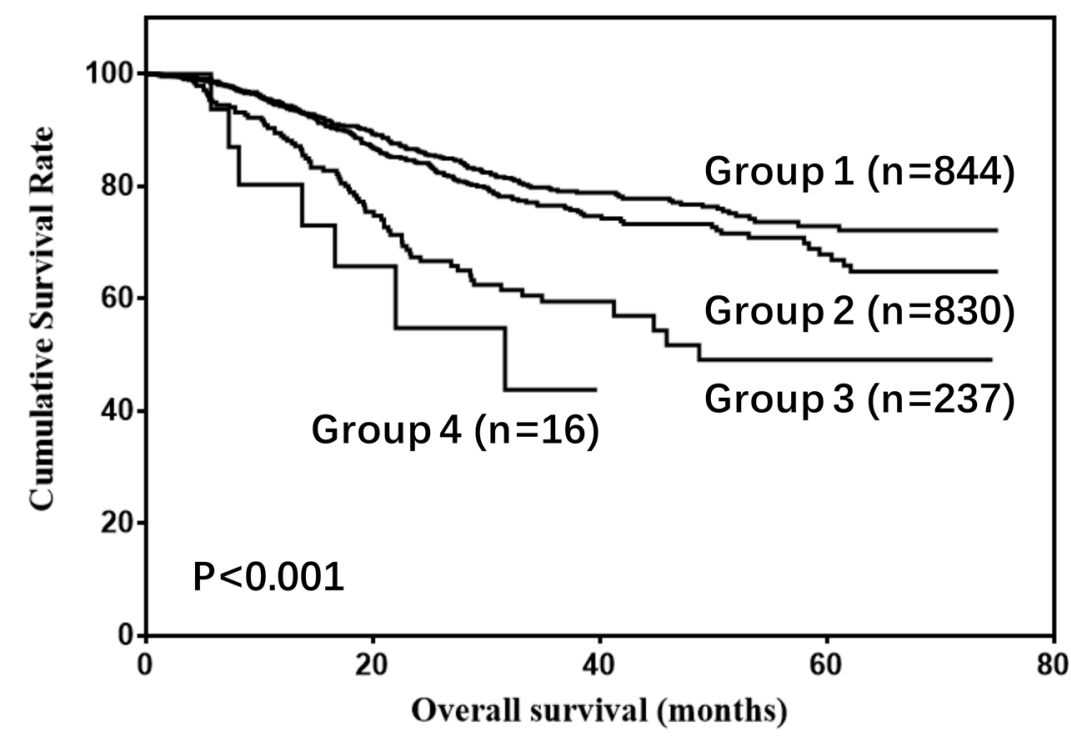

Figure 9: Overall survival of gastric cancer patients according to the combination of CA19-9, AFP, and CA125 levels. 
follow-up until November, 2015 with enhanced chest and abdominal CT and gastroscopy every 3 months.

Data were processed using SPSS 22.0 for Windows (SPSS Inc., Chicago, IL, USA). The optimal cut-off values of serum CEA, CA19-9, AFP, and CA125 for prognosis of gastric cancer were calculated using X-tile software [24]. Discrete variables were analyzed using Chi-square or Fisher's exact tests. Significant risk factors identified by univariate analysis were further assessed by multivariate analysis using logistic regression. OS was analyzed by Kaplan-Meier method. A P value of 0.05 was considered statistically significant.

\section{ACKNOWLEDGMENTS}

This study was supported in part by grants from the National Natural Scientific Foundation of China [NO. 31100643, 31570907, 81572306, 81502403, XJZT12Z03].

\section{CONFLICTS OF INTEREST}

The authors declare no conflicts of interest.

\section{REFERENCES}

1. Fock KM. Review article: the epidemiology and prevention of gastric cancer. Aliment Pharmacol Ther. 2014; 40:250-260

2. Marano L, Polom K, Patriti A, Roviello G, Falco G, Stracqualursi A, De Luca R, Petrioli R, Martinotti M, Generali D. Surgical management of advanced gastric cancer: An evolving issue. Eur J Surg Oncol. 2016; 42:18-27.

3. Hsieh FJ, Wang YC, Hsu JT, Liu KH, Yeh CN. Clinicopathological features and prognostic factors of gastric cancer patients aged 40 years or younger. J Surg Oncol. 2012; 105:304-309.

4. Huang B, Wang Z, Xing C, Sun Z, Zhao B, Xu H. Longterm survival results and prognostic factors of early gastric cancer. Exp Ther Med. 2011; 2:1059-1064.

5. Deng K, Yang L, Hu B, Wu H, Zhu H, Tang C. The prognostic significance of pretreatment serum CEA levels in gastric cancer: a meta-analysis including 14651 patients. Plos One. 2015; 10:e124151.

6. Xiao J, He X, Wang Z, Hu J, Sun F, Qi F, Yang S, Xiao Z. Serum carbohydrate antigen 19-9 and prognosis of patients with gastric cancer. Tumour Biol. 2014; 35:1331-1334.

7. Liu X, Cheng Y, Sheng W, Lu H, Xu Y, Long Z, Zhu H, Wang Y. Clinicopathologic features and prognostic factors in alpha-fetoprotein-producing gastric cancers: analysis of 104 cases. J Surg Oncol. 2010; 102:249-255.
8. Emoto S, Ishigami H, Yamashita H, Yamaguchi H, Kaisaki S, Kitayama J. Clinical significance of CA125 and CA72-4 in gastric cancer with peritoneal dissemination. Gastric Cancer. 2012; 15:154-161.

9. Song YX, Huang XZ, Gao P, Sun JX, Chen XW, Yang YC, Zhang C, Liu HP, Wang HC, Wang ZN. Clinicopathologic and Prognostic Value of Serum Carbohydrate Antigen 19-9 in Gastric Cancer: A Meta-Analysis. Dis Makers. 2015; 2015:549843.

10. Zuo C, Ju Q. An analysis on clinical characteristics and prognosis of patients with serum alpha-fetoprotein-positive gastric cancer. Minerva Med. 2015.

11. Chen Y, Qu H, Jian M, Sun G, He Q. High level of serum AFP is an independent negative prognostic factor in gastric cancer. Int J Biol Markers. 2015; 30:e387-e393.

12. Fujimura T, Kinami S, Ninomiya I, Kitagawa H, Fushida S, Nishimura G, Kayahara M, Shimizu K, Ohta T, Miwa K. Diagnostic laparoscopy, serum CA125, and peritoneal metastasis in gastric cancer. Endoscopy. 2002; 34:569-574.

13. Hwang GI, Yoo CH, Sohn BH, Shin JH, Park YL, Kim HD, Kim YS, Han WK, Pae WK. Predictive value of preoperative serum CEA, CA19-9 and CA125 levels for peritoneal metastasis in patients with gastric carcinoma. Cancer Res Treat. 2004; 36:178-181.

14. Yamamoto M, Baba H, Toh Y, Okamura T, Maehara Y. Peritoneal lavage CEA/CA125 is a prognostic factor for gastric cancer patients. J Cancer Res Clin Oncol. 2007; 133:471-476.

15. Chen S, Feng XY, Li YF, Zhao BW, Zhou ZW, Chen YB. The prognosis of gastric cancer patients with marginally elevated carcinoembryonic antigen (CEA) values after D2 radical gastrectomy. J Surg Oncol. 2013; 107:641-645.

16. Kwon OK, Yu W, Chung H. Prognostic value of postoperative CA19-9 normalization in patients with advanced gastric cancer. Hepatogastroenterology. 2013; 60:240-243.

17. Park SH, Ku KB, Chung HY, Yu W. Prognostic significance of serum and tissue carcinoembryonic antigen in patients with gastric adenocarcinomas. Cancer Res Treat. 2008; 40:16-21.

18. Ucar E, Semerci E, Ustun H, Yetim T, Huzmeli C, Gullu M. Prognostic value of preoperative CEA, CA 19-9, CA 72-4, and AFP levels in gastric cancer. Adv Ther. 2008; 25:1075-1084.

19. Sisik A, Kaya M, Bas G, Basak F, Alimoglu O. CEA and CA 19-9 are still valuable markers for the prognosis of colorectal and gastric cancer patients. Asian Pac J Cancer Prev. 2013; 14:4289-4294.

20. Kochi M, Fujii M, Kanamori N, Kaiga T, Kawakami T, Aizaki K, Kasahara M, Mochizuki F, Kasakura Y, Yamagata M. Evaluation of serum CEA and CA19-9 levels as prognostic factors in patients with gastric cancer. Gastric Cancer. 2000; 3:177-186. 
21. Liu X, Cheng Y, Sheng W, Lu H, Xu Y, Long Z, Zhu H, Wang Y. Clinicopathologic features and prognostic factors in alpha-fetoprotein-producing gastric cancers: analysis of 104 cases. J Surg Oncol. 2010; 102:249-255.

22. Kim JH, Jun KH, Jung H, Park IS, Chin HM. Prognostic Value of Preoperative Serum Levels of Five Tumor Markers (Carcinoembryonic Antigen, CA19-9,
Alpha-fetoprotein, CA72-4, and CA125) in Gastric Cancer. Hepatogastroenterology. 2014; 61:863-869.

23. Japanese gastric cancer treatment guidelines 2010 (ver. 3). Gastric Cancer. 2011; 14:113-123.

24. Camp RL, Dolled-Filhart M, Rimm DL. X-tile: a new bioinformatics tool for biomarker assessment and outcomebased cut-point optimization. Clin Cancer Res. 2004; 10:7252-7259. 